\title{
A review of low-level ionizing radiation and risk models of leukemia
}

\author{
Ting Yang • Adib Samin • Lei Cao
}

Received: 2 September 2012 /Accepted: 9 December 2012 /Published online: 28 December 2012

(C) Springer-Verlag Berlin Heidelberg 2012

\begin{abstract}
The relationship between exposure to low doses of ionizing radiation $(<100 \mathrm{mSv})$ and the risk of leukemia has perplexed researchers for decades. The recent accident in Fukushima, Japan has led to a renewed interest in better understanding this relationship, which has significant implications for government-outlined safety procedures for individuals working in occupations, such as the nuclear industry and radiology, as well as for emergency response polices on postnuclear events. Currently, the scientific community remains divided: one school of thought suggests a linear no-threshold model, while others favor a threshold-type response, and a few scientists support a hormesis response model; there is evidence in the literature to support each model. The main purpose of this article is to review and summarize the current state of knowledge and extant literature on the risk models, as well as the epidemiology of leukemia and its relationship to exposure to low doses of ionizing radiation.
\end{abstract}

Keywords Ionizing radiation $\cdot$ Low-level dose $\cdot$ Risk models $\cdot$ Leukemia $\cdot$ Dose-response curve

\section{Introduction}

Over the past few decades, scientists have investigated and debated the effects of exposure to low levels of ionizing

\section{T. Yang}

Department of Hematology, Union Hospital, Fujian Medical University, Fuzhou, China 35000

\section{A. Samin $•$ L. Cao}

Nuclear Engineering Program, The Ohio State University, Columbus, OH 43221, USA

\section{Cao $(\square)$}

Nuclear Engineering Program, The Ohio State University, 201 West 19th Avenue,

Columbus, OH 43210, USA

e-mail: cao.152@osu.edu radiation and the shape of the response curve at these low doses [1-4]. While the effects of high doses are well-known, those attributed to low doses present a much bigger investigative challenge. Given that many individuals are frequently exposed to low levels of ionizing radiation at work, it has become important to accurately characterize the relevant dose-response curve to understand the health effects and risks of repeated exposure. Moreover, the nuclear accident that occurred in Fukushima, Japan in 2011 has led to renewed interest in the field [5]. At present, there are several hypotheses to explain the correlation between low doses of ionizing radiation and the risk of cancer. The first hypothesis assumes a linear response curve, implying that no dose of ionizing radiation (no matter how small) is completely safe and that the effect of numerous small exposures will eventually resemble the effect of a large-dose exposure. The second hypothesis maintains that the dose response follows a threshold-type curve, whereby low doses are actually safe and will not lead to any increased risk of cancer. Finally, the third hypothesis $[6,7]$ suggests the idea of radiation hormesis, which implies that ionizing radiation at low levels may have beneficial effects and promote DNA repair mechanisms [8]. The purpose of this review is to summarize the current state of knowledge in this field and present important epidemiological studies that would help elucidate the application and validity of the aforementioned models.

\section{Risk models associated with low-level radiation}

Understanding the effects and risks associated with lowdose exposure has become a priority for our modern society. Diagnostic screening tests, the future of the nuclear industry, and frequent flier risks $[9,10]$ are commonly discussed issues in the media. The main problem with quantifying and accurately describing the effects of low levels of ionizing radiation is that very large epidemiological studies are required to describe the effects to a useful precision; that is, "to maintain statistical precision and power, the necessary 
sample size increases approximately as the inverse square of the dose. This relationship reflects a decline in the signal (radiation risk) to noise (natural background risk) ratio as dose decreases" [11], as shown clearly in Fig. 1.

A number of potential models have been proposed for the low-dose region (Fig. 2), including linear, linear-quadratic, supralinear, and hormesis (suggesting a threshold) models [12]. Victims of the Hiroshima and Nagasaki atomic bombs are an important source of data for determining which of these models may be tested $[6,7]$.

Brenner et al. [11] make the case for a linear response function, implying that exposure to a lower dose will only lead to fewer affected cells that will still be subject to the same type of cell damage. They conceded that these arguments are based on an assumption that the cells do not interact. The linear no-threshold (LNT) model for risk estimation has also been endorsed by the United Nations Scientific Committee on the Effects of Atomic Radiation [13] and by the International Commission on Radiological Protection [14]. The radiation-induced "bystander effect," an important phenomenon that has been observed and reported in many experimental settings [15-18], refers to the behavior of nonirradiated cells that, as a result of receiving signals from irradiated cells, still display the effects of irradiation due to the exchange of information via intercellular signaling pathways. This phenomenon may lead to the response curve divergence from linearity at low radiation doses [16-18]. Other effects observed at low doses are expressions of increased resistance and hypersensitivity (increased cell death at low doses compared with the extrapolated prediction of survival from higher dose responses (1-5 Gy)). The reason for the discrepancy is that, at very low acute doses, cells do not detect damage efficiently and thus repair mechanisms are not triggered [19]. However, as the dose increases, cells recognize damage more easily and activate repair mechanisms, which lead to cell radioresistance. As

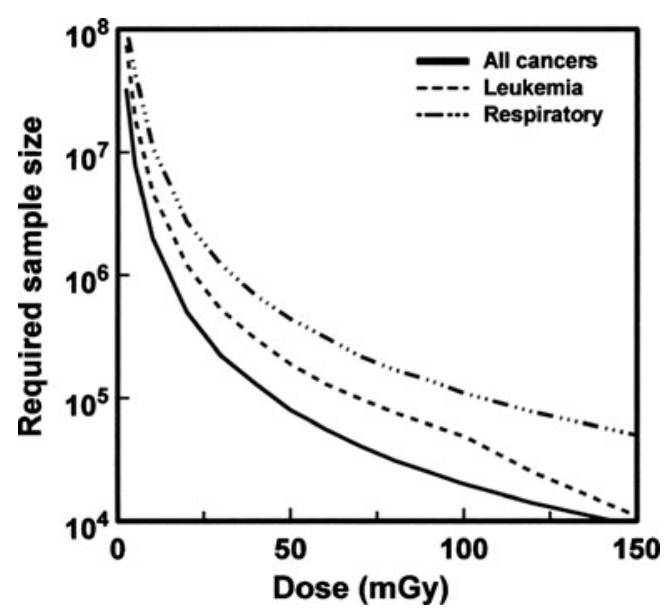

Fig. 1 Size of the cohort required to detect a significant increase in cancer mortality as a function of the radiation dose [11]

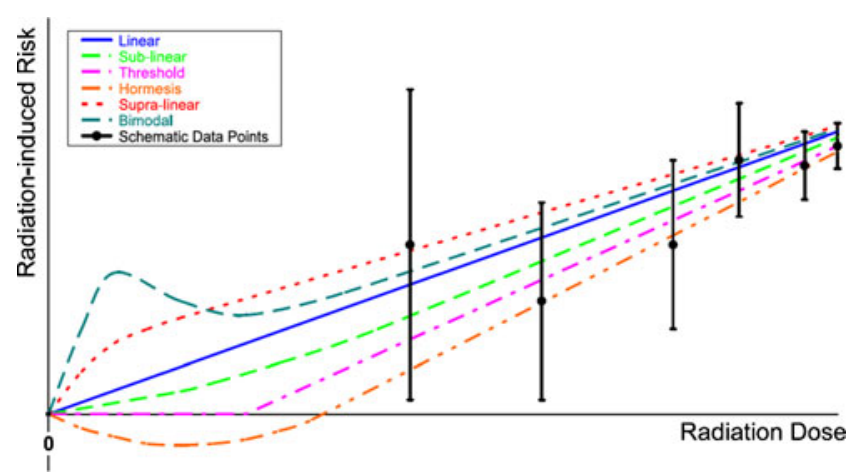

Fig. 2 Possible dose-response curves describing the excess risk of stochastic health effects at low doses of radiation [12]

Vaiserman [20] notes, "cancer risk after ordinarily encountered radiation exposure (medical X-rays, natural background radiation, etc.) is much lower than projections based on the LNT model."

Gilbert et al. [21, 22] conducted a thorough study on the mortality data of nuclear facility employees who were continuously exposed to low doses of ionizing radiation with an average dose of $<50 \mathrm{mSv}$ (primarily neutrons). They found "no evidence of a correlation" between radiation exposure and cancer and concluded that "estimates obtained through extrapolation from data at high doses have not seriously underestimated risks at low doses" [22]. Similarly, Schubauer-Berigan et al. [23] conducted a large study of radiation-exposed workers to examine the risk of leukemia. The findings suggested, however, that the quantitative leukemia risk estimates per unit of radiation dose "varied by birth cohort (and) by year of hire," which eventually made the "identification of the key effect modifiers difficult." Scott [24], meanwhile, indicated that, at approximately $1 \mathrm{mGy}$, there would be a "decrease in risk below the spontaneous level."

In contrast, Bond et al. [25] offered a fresh perspective by carefully defining the concept of a dose $(D)$ and considering the total energy in the irradiated system $(\varepsilon)$ as:

$\varepsilon=m D$

where $m$ is the total mass of the system (e.g., human tissue) that is being irradiated. Their analysis of data from Japanese atomic bomb survivors suggests that a minimum energy $\left(\varepsilon_{0}\right)$ rather than a threshold dose is required for excess cancer occurrence; they calculated an approximate threshold value of $\sim 3 \mathrm{~kJ}$ as a minimum for cancers other than leukemia to occur [24].

The excess leukemia risk observed among survivors of the Hiroshima bomb was indicated by Land [26] to be significantly greater than that observed among Nagasaki survivors exposed to similar estimated dose levels [27-29], which suggests that neutrons may be more effective than gamma rays in causing leukemia [30]. Land further observed that the linear- 
quadratic model is "preferable" to the linear model by explaining that the presence of a "densely ionizing part of all gamma ray tracks" means that the linear dose coefficient cannot be zero [26].

A competing model, the threshold-type response curve, has found support among other researchers [31, 32]. Kathren [32] argues that many factors, such as the latency period and dose rate, need to be accounted for when considering the human response to radiation and proposes a Gompertzian model to depict this response (Fig. 3). The Gompertzian model can be divided into two response functions: one that characterizes the deterministic effects and another that shows the stochastic effects.

\section{Controversy regarding risk models}

Numerous scientists support the view that exposure to low doses of ionizing radiation is actually beneficial, promoting DNA repair and antioxidative capacity and inducing apoptosis in transformed cells [33-37]. Figure 4 illustrates the hormetic relative risk (HRR) model proposed by Scott et al. [35]; the population average relative risk (RR) is plotted against the total absorbed dose $(D)$.

As explained in [35], stochastic thresholds for stimulating adaptive-response genes occur in the interval $0-D^{*}$ (transition zone A). Stochastic thresholds for adaptiveresponse gene silencing occur in the interval from $D^{* *}$ to $D^{* * *}$ (transition zone $\mathrm{B}$ ), and the linear zone is assumed to begin for doses over $D^{* * *}$, at which point all gene adaptive responses have been silenced.

This model seems to be supported by various other experiments. Sakai et al. [33] investigated the effects of low levels of gamma radiation on mice treated with a carcinogenic agent or exposed to high doses of X-rays. The results (Table 1) show that prolonged gamma irradiation,

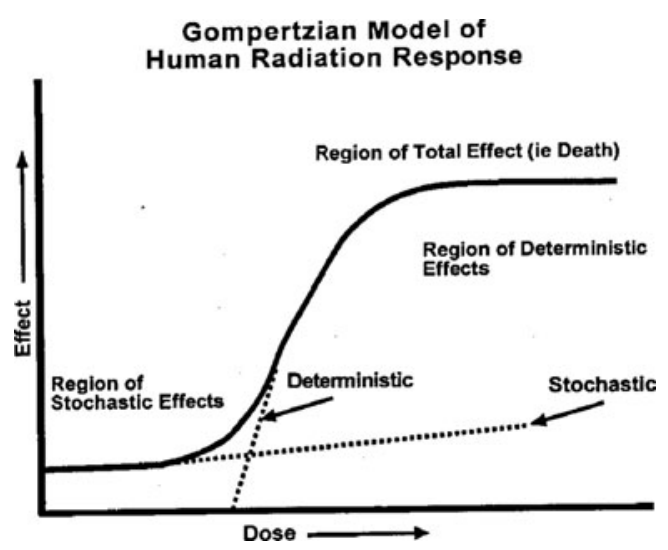

Fig. 3 Stylized human radiation dose-response curve as depicted by Kathren [32]

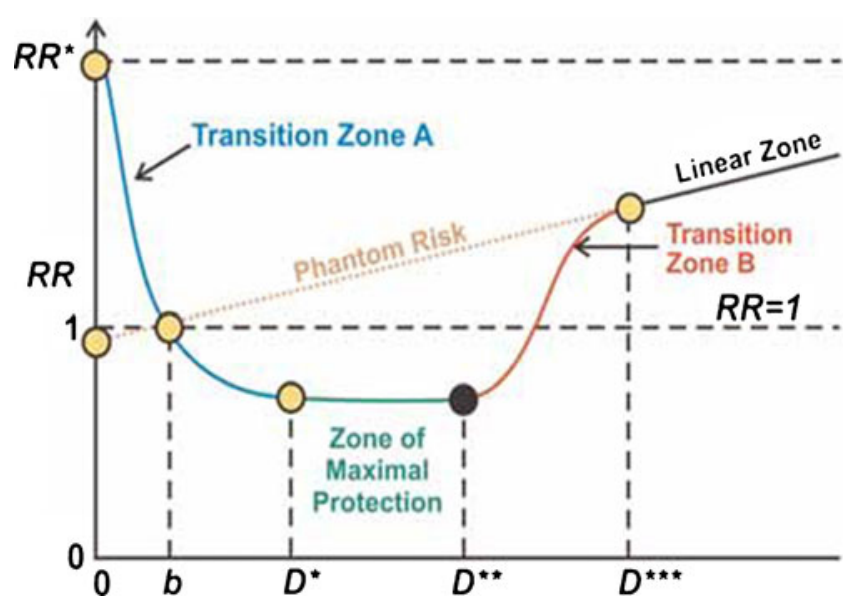

Fig. 4 Schematic representation of the cancer RR as a function of the dose relationships according to the HRR model [35]

at approximately $1.2 \mathrm{mGy} / \mathrm{h}$, suppressed the tumorigenic process and increased the immune response of mixed lymphocyte reaction-lpr/lpr (MLR-lpr) mice (which have a deletion of an apoptosis-regulating gene, Fas, that leads to autoimmune diseases).

Additionally, an earlier experiment [38], in which mice were irradiated at various dose rates for 35 days with ${ }^{137} \mathrm{Cs}$ gamma rays and then injected with methylcholanthrene (MC), concluded that suppression of tumorigenesis with low-dose irradiation occurred at an optimum dose rate of $1 \mathrm{mGy} / \mathrm{h}$ (Table 2).

Evidence in support of hormesis was also presented by Rithidech et al. [39] who demonstrated gamma ray hormesis during low-dose neutron irradiation. Additionally, Scott and Di Palma [40] conducted a thorough investigation of the effects of the natural background radiation used in medical diagnostic procedures and found that the "environmental radiation hormesis associated with radon" and "elevated background radiation" appear to be "preventing many cancer deaths." Furthermore, they found that diagnostic medical procedures, such as chest X-rays and mammograms, also prevent cancer by "stimulating the removal of precancerous neoplastically transformed cells" and stated that protracted

Table 1 Effects of low-dose-rate irradiation on the survival of MLRlpr mice [33]

\begin{tabular}{llll}
\hline Age (days) & \multicolumn{3}{l}{ Survival (\%) } \\
\cline { 2 - 4 } & $0 \mathrm{mGy} / \mathrm{h}$ & $0.35 \mathrm{mGy} / \mathrm{h}$ & $1.2 \mathrm{mGy} / \mathrm{h}$ \\
\hline 100 & 100 & 100 & 100 \\
125 & 67 & 100 & 100 \\
150 & 0 & 83 & 100 \\
175 & 0 & 25 & 100 \\
200 & 0 & 17 & 83 \\
\hline
\end{tabular}


Table 2 Tumor incidence after the injection of $\mathrm{MC}$ for mice irradiated under various conditions [38]

\begin{tabular}{lllll}
$\begin{array}{l}\text { Days after } \\
\text { MC injection }\end{array}$ & $\begin{array}{l}\text { Nonirradiated } \\
\text { control }\end{array}$ & $0.30 \mathrm{mGy} / \mathrm{h}$ & $0.95 \mathrm{mGy} / \mathrm{h}$ & $2.6 \mathrm{mGy} / \mathrm{h}$ \\
\hline 100 & 40 & 31 & 14 & 20 \\
150 & 71 & 86 & 61 & 71 \\
200 & 94 & 91 & 76 & 86 \\
216 & 94 & 94 & 76 & 89 \\
\hline
\end{tabular}

The tumor incidence is presented as the percentage of mice with tumors

exposure to small X-ray doses has been used to successfully treat non-Hodgkin lymphoma and other cancers [40]. In another study [37], it was concluded that an increased risk of lung cancer from ionizing radiation at lung doses of $<1$ Gy was not observed in exposed never-smokers, thus suggesting that gamma rays protect against the stochastic effects of alpha dose radiation and may enhance the apoptosis of chemically transformed cells.

Nevertheless, as Puskin notes in [41], it is unlikely that governmental agencies will shift their policies away from the LNT model unless it is clearly demonstrated that the model greatly overestimates the risk of low radiation doses. Additionally, the Biologic Effects of Ionizing Radiation (BEIR) VII report [42] from the US National Academies, one of the main reports directing radiation policy, concluded that the balance of experimental evidence favors a "simple proportionate relationship at low doses" between radiation dose and cancer risk.

In response to Puskin's article [41], Cuttler [43] criticized the LNT model by suggesting that it is currently accepted that organisms have DNA repair mechanisms that may be activated following low doses of radiation and that "although the LNT model is still widely accepted, it does not reflect reality." The discrepancy between the LNT model and the experimental data was raised again by Tubiana et al. [44] who conducted a review of relevant radiation biology experiments and concluded that the LNT model for low doses of ionizing radiation lacks "scientific justification," citing the Chernobyl incident as an example in which overestimating the risk may be more dangerous than underestimating it. ${ }^{1}$ An earlier report suggested that the lack of evidence of carcinogenic effects for doses below $100 \mathrm{mSv}$ could be attributed to two possible explanations: either the carcinogenic effect is too small to be detected by statistical analysis or there is no effect and a practical threshold exists [45].

\footnotetext{
${ }^{1}$ The spread of misinformation was suggested to be partially responsible for fueling anxiety, which ultimately led to evacuations, elective abortions, and suicides.
}

\section{Epidemiology of leukemia in relation to low doses of ionizing radiation}

Atomic bomb survivors

A number of studies [46-50], conducted in the 1950s, examined the incidence of leukemia among atomic bomb survivors. Preston et al. [49] later analyzed the data for a life span study cohort of 93,696 atomic bomb survivors for the period from 1950 to 1987 . They concluded that there was "strong evidence" of radiation-induced risks for all subtypes of leukemia, except adult T cell leukemia. Within the study population, there was also evidence of an increased risk of lymphoma in males but not in females. Later studies of 30,000 children of atomic bomb survivors showed a lack of significant adverse genetic effects [42].

Residents close to a nuclear weapon facility

The risk of leukemia among residents of the Techa River banks who were exposed to chronic low-dose-rate internal and external radiation due to the Mayak nuclear weapons plutonium production facility in Russia was studied using 83 cases with 47 years of follow-up and 415 controls [51]. Radiation was released both into the Techa River and into the air. The odds ratios per gray of total, external, and internal doses were 4.6 (95\% confidence interval (CI), 1.7-12.3), 7.2 (95\% CI, 1.7-30.0), and 5.4 (95\% CI, 1.1-27.2), respectively. The analysis confirmed an association between nonchronic lymphoid leukemia (CLL) risk and prolonged exposure to radiation.

The incidence of leukemia among these residents was further examined by Krestinina et al. [52] who reported on a follow-up of 30,000 exposed individuals, who resided in riverside villages between 1950 and 1960, from 1953 to 2005. The mean and median reported bone marrow doses were 0.3 and $0.2 \mathrm{~Gy}$, respectively. A "significant" linear dependence on dose was reported for non-CLL.

\section{Chernobyl cleanup workers}

Romanenko et al. [53] conducted a case-control study on the incidence of leukemia among Chernobyl cleanup workers in Ukraine who were subject to fractionated exposure, primarily from gamma radiation. A conditional logistic regression analysis was used to estimate the leukemia risk, and the data were based on the diagnosis of 71 cases during the period from 1986 to 2000 , with the mean recorded bone marrow dose reported as $76.4 \mathrm{mGy}$. A linear dose-response relationship for both CLL and non-CLL was also observed. In a similar study [54], 70 cases (40 leukemia, 20 nonHodgkin lymphoma, and 10 other blood-related malignancies) were examined, and the median dose to the bone 
marrow was reported as 13 mGy. The reported excess RR figures were concluded to be "slightly higher but statistically compatible" with the data from atomic bomb victims and other studies conducted on low-dose radiation.

\section{Nuclear power industry workers}

Wilkinson and Dreyer [55] studied nuclear workers who were frequently exposed to low doses of ionizing radiation. Their analysis consisted of 7 different studies, including 83 leukemia deaths, and detected clear evidence of "a modest excess of leukemia" from exposure to doses of $<10 \mathrm{mSv}$.

Zablotska et al. [56] published a study that analyzed mortality after chronic exposure to low-dose ionizing radiation based on a cohort of 45,468 nuclear workers. The mean monitoring duration time was 7.4 years, with the mean cumulative equivalent dose reported as $13.3 \mathrm{mSv}$. A "monotonic" increase in the RR by dose categories for leukemia (excluding CLL) was observed. In a similar study, Ritz et al. [57] analyzed the effects among 4,563 nuclear workers monitored for external radiation between 1950 and 1993 . The results indicated (through external comparisons) a higher rate of death attributed to leukemia and (by internal comparisons) an increased death rate for workers exposed to more than $200 \mathrm{mSv}$ for hematopoietic and lymphopoietic cancers. This observed surge in mortality was suggested to be due to protracted exposure to radiation levels that were acceptable under US government standards. A study by Guerin et al. [58] among 9,815 French nuclear industry workers monitored between 1967 and 2000 for exposure to ionizing radiation (X-rays and gamma rays) showed "no excess compared with the general population" when cancer sites were analyzed. The median cumulative dose for that study was $4.8 \mathrm{mSv}$; however, the study had several drawbacks, one of which was a "strong" healthy worker effect $(\mathrm{HWE})^{2}$. A 15-country collaborative cohort study to better characterize the cancer risks was conducted with 407,391 nuclear workers, and the risk estimate for leukemia excluding CLL was found to be "not significantly different from zero" [59]. The HWE hypothesis was also used in that study to explain the decreased standard mortality ratios (SMR) with increased employment duration. However, Fornalski and Dobrzynski [8] reexamined data from the International Agency for Research on Cancer using conventional least squares tests and Bayesian statistical methods and showed that the SMR are lower in the exposed cohort than in the nonexposed cohort. Further, they noted that a number of important studies showed a similar trend of "substantial decreases in cancer mortality" compared with the nonexposed reference group and consequently dismissed the

\footnotetext{
$\overline{2}$ There is some statistical bias, as most people who work in laborintensive professions are in good health.
}

HWE statistical bias as being a plausible explanation for the results.

Cartwright [60] reported an excess of leukemia among radiologists using equipment prior to 1920 (both in the UK and the USA) and further noted that several UK nuclear sites had reported excessive leukemia cases, noting that another study showed a similar excess in areas designated for, but not built on, a nuclear site, thus suggesting inconsistencies. Finally, Cartwright's review of the effect of background radiation was inconclusive but consistent with other research [46, 61, 62].

Daniels and Schubauer-Berigan [63] conducted a casecontrol investigation of 23 studies on the relationship between prolonged exposure to ionizing radiation and leukemia. The primary exposure evaluated was the external radiation dose to the bone marrow from high-energy photons, lower-energy photons, neutrons, and tritium. The results of a conditional logistic regression suggested that the "risks among nuclear workers are comparable to those observed in high-dose populations" [63].

\section{Medical and radiological workers}

The cancer risk for 27,011 medical diagnostic X-ray workers in China between 1950 and 1995 was examined using the observed/expected system [64]. The study noted that a "significant" cancer risk may be induced by long-term fractionated exposure to low doses of ionizing radiation "when the cumulative dose reaches a certain level."

Scott et al. [65] attempted to characterize the impact of diagnostic computed tomography (CT) scans on the risk of cancer in the US population; the study concluded that CT scans "may reduce rather than increase the lifetime cancer risk" and that sporadic exposure to diagnostic X-rays may reduce the future risk of tumorigenesis among irradiated adults.

Muirhead et al. [66] examined a cohort of 174,541 following occupational radiation exposure. The study was primarily focused on doses associated with X-rays and gamma rays, and the mean lifetime dose was $24.9 \mathrm{mSv}$. They established that "raised risks" of leukemia (excluding CLL) were observed among Japanese atomic bomb survivors, radiotherapy patients, and large groups of radiation workers. The subtype of leukemia showing the strongest association with radiation was found to be chronic myelogenous leukemia.

Risk of childhood cancer

A characterization of the risk of childhood cancer per unit dose of radiation received in utero was attempted by Wakeford and Little [67] using data derived from the largest casecontrol study of obstetric X-ray examinations. The authors 
concluded their study with a "cause and effect" interpretation of the association between childhood cancer and diagnostic Xray exposure to the fetus. Additionally, they determined that the risk of childhood cancer from acute intrauterine doses of approximately $10 \mathrm{mSv}$ is not zero.

Busby [68] conducted an exhaustive investigation of infant leukemia in the UK, Germany, Greece, and Belarus, where the doses absorbed by the fetuses were $0.02,0.06$, 0.2 , and $2 \mathrm{mSv}$, respectively. Following a study on leukemia in the combined population of $15,466,854$ between 1980 and 1990, Busby reported an excess RR of 1.43 and argued in favor of a "biphasic model" due to the "induced repair efficiency."

A case-control investigation by Davis et al. [69] of the risk of leukemia in children following exposure to radionuclides from the Chernobyl power plant explosion found a "significant increase in leukemia risk with increasing radiation dose to the bone marrow." The median estimated radiation dose of the participants was $<10 \mathrm{~Gy}$. Kaatsch et al. [70] released a report on the incidence of leukemia among German children under 5 years of age in the inner $5-\mathrm{km}$ zone around nuclear plants; they reported a significant increase in leukemia. However, a review of the study by Zolzer [71] emphasized that the measured radiation doses were insufficient to account for the observed leukemia cases and further explained that similar increases had been observed near "planning sites," where no nuclear facility had ever been built. Moreover, Laurier et al. [72] indicated that "no similar excesses have been observed in studies from other countries."

Finally, the BEIR VII report [42] suggested a correlation between the incidence of leukemia and gender, age at exposure, and time since exposure.

\section{Summary}

Several models have been suggested to explain the relationship between exposure to low doses of ionizing radiation $(<100 \mathrm{mSv})$ and the risk of leukemia. These models include the LNT model, threshold response model, and hormetic response model. In this review, we have outlined these models and presented the arguments and observations supporting each model. We have also provided a general overview of the critical studies on the epidemiology of leukemia with respect to exposure to low doses of ionizing radiation. A further understanding of the health effects of low doses of ionizing radiation is important for determining government policies concerning the use of radiation for human health, as well as for emergency response policies for postnuclear events.

Conflicts of interest The authors report no conflicts of interest.

\section{References}

1. Charles MW (2006) LNT - an apparent rather than a real controversy? J Radiol Prot 26:325-329. doi:10.1088/0952-4746/26/3/N02

2. Tubiana M, Aurengo A, Averbeck D, Masse R (2006) The debate on the use of linear no threshold for assessing the effects of low doses. J Radiol Prot 26:317-324. doi:10.1088/0952-4746/26/3/N01

3. Moysich KB, Menezes RJ, Michalek AM (2002) Chernobylrelated ionising radiation exposure and cancer risk: an epidemiological review. Lancet Oncol 3:269-279. doi:10.1016/S1470-2045 (02)00727-1

4. Boice JD, Lubin JH (1997) Occupational and environmental radiation and cancer. Cancer Causes Control 8:309-322. doi:10.1023/ A:1018496919324

5. Scott BR (2011) Assessing potential radiological harm to Fukushima recovery workers. Dose-response 9:301-312. doi:10.2203/doseresponse.11-004.Scott

6. Mine M, Okumura Y, Ichimaru M, Nakamura T, Kondo S (1990) Apparently beneficial effect of low to intermediate doses of Abomb radiation on human lifespan. Int J Radiat Biol 58:10351043. doi:10.1080/09553009014552341

7. Luckey TD (2008) Atomic bomb health benefits. Dose-response 6:369-382. doi:10.2203/dose-response.08-009.Luckey

8. Fornalski KW, Dobrzyński L (2010) The healthy worker effect and nuclear industry workers. Dose-response 8:125-147. doi:10.2203/ dose-response.09-019.Fornalski

9. Band PR, Le ND, Fang R, Deschamps M, Coldman AJ, Gallagher RP, Moody J (1996) Cohort study of Air Canada pilots: mortality, cancer incidence, and leukemia risk. Am J Epidemiol 143:137-143

10. Gundestrup M, Storm HH (1999) Radiation-induced acute myeloid leukaemia and other cancers in commercial jet cockpit crew: a population-based cohort study. Lancet 354:2029-2031. doi:10.1016/S0140-6736(99)05093-X

11. Brenner DJ, Doll R, Goodhead DT et al (2003) Cancer risks attributable to low doses of ionizing radiation: assessing what we really know. Proc Natl Acad Sci U S A 100:13761-13766. doi:10.1073/pnas.2235592100

12. Wakeford R (2009) Radiation in the workplace - a review of studies of the risks of occupational exposure to ionising radiation. J Radiol Prot 29:A61-A79. doi:10.1088/0952-4746/29/2A/S05

13. United Nations Scientific Committee on the Effects of Atomic Radiation (2006) Effects of ionizing radiation. Available at http://www. unscear.org/docs/reports/2006/07-82087_Report_2006_Web.pdf

14. ICRP (1991) 1990 Recommendations of the International Commission on Radiological Protection. ICRP Publication 60. Ann ICRP 21 (1-3). Pergamon, Oxford

15. Klammer H, Kadhim M, Iliakis G (2010) Evidence of an adaptive response targeting DNA nonhomologous end joining and its transmission to bystander cells. Cancer Res 70:8498-8506. doi:10.1158/ 0008-5472.CAN-10-1181

16. Little MP (2010) Do non-targeted effects increase or decrease low dose risk in relation to the linear-non-threshold (LNT) model? Mutat Res Fundam Mol Mech Mutagen 687:17-27. doi:10.1016/ j.mrfmmm.2010.01.008

17. Mothersill C, Seymour CB, Joiner MC (2002) Relationship between radiation-induced low-dose hypersensitivity and the bystander effect. Radiat Res 157:526-532. doi:10.1667/0033-7587 (2002)157[0526:RBRILD]2.0.CO;2

18. Higson DJ (2004) The bell tolls for LNT. Health Phys 87:S47-S50

19. Joiner MC (1994) Induced radioresistance-an overview and historical perspective. Int J Radiat Biol 65:79-84. doi:10.1080/ 09553009414550111

20. Vaiserman AM (2010) Radiation hormesis: historical perspective and implications for low-dose cancer risk assessment. Dose-response 8:172-191. doi:10.2203/dose-response.09-037.Vaiserman 
21. Gilbert ES, Cragle DL, Wiggs LD (1993) Updated analyses of combined mortality data for workers at the Hanford Site, Oak Ridge National Laboratory, and Rocky Flats Weapons Plant. Radiat Res 136:408-421. doi:10.2307/3578555

22. Gilbert ES, Fry SA, Wiggs LD, Voelz GL, Cragle DL, Petersen GR (1989) Analyses of combined mortality data on workers at the Hanford Site, Oak Ridge National Laboratory, and Rocky Flats Nuclear Weapons Plant. Radiat Res 120:19-35. doi:10.2307/3577633

23. Schubauer-Berigan MK, Daniels RD, Fleming DA, Markey AM, Couch JR, Ahrenholz SH, Burphy JS, Anderson JL, Tseng C-Y (2007) Risk of chronic myeloid and acute leukemia mortality after exposure to ionizing radiation among workers at four U.S. nuclear weapons facilities and a nuclear naval shipyard. Radiat Res 167:222-232. doi:10.1667/RR0724.1

24. Scott BR (2008) Low-dose radiation risk extrapolation fallacy associated with the linear-no-threshold model. Hum Exp Toxicol 27:163-168. doi:10.1177/0960327107083410

25. Bond VP, Benary V, Sondhaus CA (1991) A different perception of the linear, nonthreshold hypothesis for low-dose irradiation. Proc Natl Acad Sci U S A 88:8666-8670

26. Land CE (1980) Estimating cancer risks from low doses of ionizing radiation. Science 209:1197-1203. doi:10.1126/science.7403879

27. Ichimaru M, Ishimaru T, Belsky JL (1978) Incidence of leukemia in atomic bomb survivors belonging to a fixed cohort in Hiroshima and Nagasaki, 1950-71. Radiation dose, years after exposure, age at exposure, and type of leukemia. J Radiat Res 19:262-282. doi:10.1269/jrr.19.262

28. Ishimaru T, Otake M, Ichimaru M (1979) Dose-response relationship of neutrons and $\gamma$ rays to leukemia incidence among atomic bomb survivors in Hiroshima and Nagasaki by type of leukemia, 1950-1971. Radiat Res 77:377-394. doi:10.2307/3575148

29. Rossi HH, Kellerer AM (1974) The validity of risk estimates of leukemia incidence based on Japanese data. Radiat Res 58:131140. doi: $10.2307 / 3573926$

30. Kellerer AM, Rossi HH (1978) A generalized formulation of dual radiation action. Radiat Res 75:471-488. doi:10.2307/3574835

31. Tanooka H (2001) Threshold dose-response in radiation carcinogenesis: an approach from chronic $\beta$-irradiation experiments and a review of non-tumour doses. Int J Radiat Biol 77:541-551. doi:10.1080/09553000110034612

32. Kathren RL (1996) Pathway to a paradigm: the linear nonthreshold dose-response model in historical context. The American Academy of Health Physics 1995 Radiology Centennial Hartman Oration. Health Phys 70:621-635

33. Sakai K, Nomura T, Ina Y (2006) Enhancement of bio-protective functions by low dose/dose-rate radiation. Dose-response 4:327332. doi:10.2203/dose-response.06-115.Sakai

34. Thompson RE (2011) Epidemiological evidence for possible radiation hormesis from radon exposure: a case-control study conducted in Worcester, MA. Dose-response 9:59-75. doi:10.2203/ dose-response.10-026.Thompson

35. Scott BR, Belinsky SA, Leng S, Lin Y, Wilder JA, Damiani LA (2009) Radiation-stimulated epigenetic reprogramming of adaptive-response genes in the lung: an evolutionary gift for mounting adaptive protection against lung cancer. Dose-response 7:104-131. doi:10.2203/dose-response.08-016.Scott

36. Bauer G (2007) Low dose radiation and intercellular induction of apoptosis: potential implications for the control of oncogenesis. Int J Radiat Biol 83:873-888. doi:10.1080/09553000701727523

37. Sanders CL, Scott BR (2008) Smoking and hormesis as confounding factors in radiation pulmonary carcinogenesis. Dose-response 6:53-79. doi:10.2203/dose-response.06-003.Sanders

38. Sakai K, Hoshi Y, Nomura T, Oda T, Iwasaki T, Fujita K, Yamada T, Tanooka H (2003) Suppression of carcinogenic processes in mice by chronic low dose rate gamma-irradiation. Int J Low Radiat 1:142-146
39. Rithidech KN, Scott BR (2008) Evidence for radiation hormesis after in vitro exposure of human lymphocytes to low doses of ionizing radiation. Dose-response 6:252-271. doi:10.2203/doseresponse.07-024.Rithidech

40. Scott BR, Di Palma J (2007) Sparsely ionizing diagnostic and natural background radiations are likely preventing cancer and other genomic-instability-associated diseases. Dose-response 5:230-255. doi:10.2203/dose-response.06-002.Scott

41. Puskin JS (2009) Perspective on the use of LNT for radiation protection and risk assessment by the US Environmental Protection Agency. Dose-response 7:284-291. doi:10.2203/doseresponse.09-005.Puskin

42. Committee to Assess Health Risks from Exposure to Low Level of Ionizing Radiation, National Research Council (2006) Health risks from exposure to low levels of ionizing radiation: BEIR VII Phase 2. National Academies Press, Washington, DC

43. Cuttler JM (2009) Commentary on using LNT for radiation protection and risk assessment. Dose-response 8:378-383. doi:10.2203/dose-response.10-003.Cuttler

44. Tubiana M, Feinendegen LE, Yang C, Kaminski JM (2009) The linear no-threshold relationship is inconsistent with radiation biologic and experimental data. Radiology 251:13-22. doi:10.1148/ radiol.2511080671

45. Tubiana M (2005) Dose effect relationship and estimation of the carcinogenic effects of low doses of ionizing radiation: the joint report of the Académie des Sciences (Paris) and of the Académie Nationale de Médecine. Int J Radiat Oncol Biol Phys 63:317-319. doi:10.1016/j.ijrobp.2005.06.013

46. Schwartz EE, Upton AC (1958) Factors influencing the incidence of leukemia - special consideration of the role of ionizing radiation. Blood 13:845-864

47. Moloney WC, Lange RD (1954) Leukemia in atomic bomb survivors. II. Observations on early phases of leukemia. Blood 9:663-685

48. Richardson D, Sugiyama H, Nishi N et al (2009) Ionizing radiation and leukemia mortality among Japanese atomic bomb survivors, 1950-2000. Radiat Res 172:368-382. doi:10.1667/RR1801.1

49. Preston DL, Kusumi S, Tomonaga M et al (1994) Cancer incidence in atomic bomb survivors. Part III. Leukemia, lymphoma and multiple myeloma, 1950-1987. Radiat Res 137:S68-S97. doi: $10.2307 / 3578893$

50. Lange RD, Moloney WC, Yamawaki T (1954) Leukemia in atomic bomb survivors. I. General observations. Blood 9:574-585

51. Ostroumova E, Gagnière B, Laurier D et al (2006) Risk analysis of leukaemia incidence among people living along the Techa River: a nested case-control study. J Radiol Prot 26:17-32. doi:10.1088/ 0952-4746/26/1/001

52. Krestinina L, Preston DL, Davis FG, Epifanova S, Ostroumova E, Ron E, Akleyevet A (2010) Leukemia incidence among people exposed to chronic radiation from the contaminated Techa River, 1953-2005. Radiat Environ Biophys 49:195-201. doi:10.1007/ s00411-009-0257-5

53. Romanenko AY, Finch SC, Hatch M et al (2008) The UkrainianAmerican study of leukemia and related disorders among Chornobyl cleanup workers from Ukraine: III. Radiation risks. Radiat Res 170:711-720. doi:10.1667/RR1404.1

54. Kesminiene A, Evrard A-S, Ivanov VK et al (2008) Risk of hematological malignancies among Chernobyl liquidators. Radiat Res 170:721-735. doi:10.1667/RR1231.1

55. Wilkinson GS, Dreyer NA (1991) Leukemia among nuclear workers with protracted exposure to low-dose ionizing radiation. Epidemiology 2:305-309. doi:10.2307/20065685

56. Zablotska LB, Ashmore JP, Howe GR (2004) Analysis of mortality among Canadian nuclear power industry workers after chronic low-dose exposure to ionizing radiation. Radiat Res 161:633641. doi:10.1667/RR3170 
57. Ritz B, Morgenstern H, Froines J, Young BB (1999) Effects of exposure to external ionizing radiation on cancer mortality in nuclear workers monitored for radiation at Rocketdyne/Atomics International. Am J Ind Med 35:21-31. doi:10.1002/(SICI)10970274(199901)35:1<21::AID-AJIM4>3.0.CO;2-X

58. Guérin S, Richard G, Biau A, Lebre S, Crescini D, Haddy N, Guldner L, Paoletti C, Hill C, de Vathaire F (2009) Cancer mortality among French nuclear contract workers. Am J Ind Med 52:916-925. doi:10.1002/ajim.20768

59. Cardis E, Vrijheid M, Blettner M et al (2007) The 15-country collaborative study of cancer risk among radiation workers in the nuclear industry: estimates of radiation-related cancer risks. Radiat Res 167:396-416. doi:10.1667/RR0553.1

60. Cartwright RA (1992) Leukaemia epidemiology and radiation risks. Blood Rev 6:10-14. doi:10.1016/0268-960X(92)90003-9

61. Segall A (1964) Leukemia and background radiation in Northern New England. Blood 23:250-261

62. Craig L, Seidman H (1961) Leukemia and lymphoma mortality in relation to cosmic radiation. Blood 17:319-327

63. Daniels RD, Schubauer-Berigan MK (2011) A meta-analysis of leukaemia risk from protracted exposure to low-dose gamma radiation. Occup Environ Med 68:457-464. doi:10.1136/ oem.2009.054684

64. Wang JX, Zhang LA, Li BX, Zhao YC, Wang ZQ, Zhang JY, Aoyama $\mathrm{T}$ (2002) Cancer incidence and risk estimation among medical X-ray workers in China, 1950-1995. Health Phys 82:455-466

65. Scott BR, Sanders CL, Mitchel REJ, Boreham DR (2008) CT scans may reduce rather than increase the risk of cancer. J Am Physicians Surg 13:8-11
66. Muirhead CR, O’Hagan JA, Haylock RG, Phillipson MA, Willcock T, Berridge GL, Zhang W (2009) Mortality and cancer incidence following occupational radiation exposure: third analysis of the $\mathrm{Na}-$ tional Registry for Radiation Workers. Br J Cancer 100:206-212. doi: doi:10.1038/sj.bjc.6604825

67. Wakeford R, Little MP (2003) Risk coefficients for childhood cancer after intrauterine irradiation: a review. Int J Radiat Biol 79:293-309. doi:10.1080/0955300031000114729

68. Busby CC (2009) Very low dose fetal exposure to Chernobyl contamination resulted in increases in infant leukemia in Europe and raises questions about current radiation risk models. Int $\mathrm{J}$ Environ Res Public Health 6:3105-3114. doi:10.3390/ ijerph6123105

69. Davis S, Day RW, Kopecky KJ et al (2006) Childhood leukaemia in Belarus, Russia, and Ukraine following the Chernobyl power station accident: results from an international collaborative population-based case-control study. Int J Epidemiol 35:386396. doi:10.1093/ije/dyi220

70. Kaatsch P, Spix C, Schulze-Rath R, Schmiedel S, Blettner M (2008) Leukaemia in young children living in the vicinity of German nuclear power plants. Int J Cancer 122:721-726. doi:10.1002/ijc. 23330

71. Zolzer F (2010) Childhood leukaemia in the vicinity of German nuclear power plants - some missing links. J Appl Biomed 8:6772. doi:10.2478/v10136-009-0010-z

72. Laurier D, Jacob S, Bernier MO, Leuraud K, Metz C, Samson E, Laloi P (2008) Epidemiological studies of leukaemia in children and young adults around nuclear facilities: a critical review. Radiat Prot Dosimetry 132:182-190. doi:10.1093/rpd/ncn262 